Faculty of Engineering

Faculty Publications

Modeling the Effect of Chemical Membrane Degradation on PEMFC Performance R. Singh, P. C. Sui, K. H. Wong, E. Kjeang, S. Knights, and N. Djilali April 2018

(c) The Author(s) 2018. Published by ECS. This is an open access article distributed under the terms of the Creative Commons Attribution Non-Commercial No Derivatives 4.0 License (CC BY-NC-ND, http://creativecommons.org/licenses/by-ncnd/4.0/), which permits non-commercial reuse, distribution, and reproduction in any medium, provided the original work is not changed in any way and is properly cited. For permission for commercial reuse, please email: oa@electrochem.org

This article was originally published at:

http://dx.doi.org/10.1149/2.0351806jes

Citation for this paper:

Singh, R., Sui, P.C., Wong, K.H., Kjeang, E., Knights, S. \& Djilali, N. (2018). Modeling the Effect of Chemical Membrane Degradation on PEMFC Performance. Journal of the Electrochemical Society, (165)6, F3328-F3336. 
Jes focus Issue on Proton Exchange Membrane Fuel Cell (PEMFC) Durability

\title{
Modeling the Effect of Chemical Membrane Degradation on PEMFC Performance
}

\author{
R. Singh, ${ }^{1, a}$ P. C. Sui, ${ }^{1,2}$ K. H. Wong, ${ }^{3}$ E. Kjeang, $\oplus^{3, *}$ S. Knights, ${ }^{4, *}$ and N. Djilali $\circledast^{1, *, z}$ \\ ${ }^{I}$ Institute for Integrated Energy Systems and Department of Mechanical Engineering, University of Victoria, Victoria, \\ BC V8W 3P6, Canada \\ ${ }^{2}$ School of Automotive Engr., Wuhan University of Technology, Wuhan, Hubei, People's Republic of China \\ ${ }^{3}$ School of Mechatronic Systems Engr., Simon Fraser University, Surrey, BC, Canada \\ ${ }^{4}$ Ballard Power Systems, Burnaby, Canada
}

\begin{abstract}
A transient, isothermal, two-dimensional model coupling cell performance and chemical membrane degradation in a polymer electrolyte membrane fuel cell (PEMFC) is developed. The model is based on the conservation of and thermodynamic equilibrium between charged and neutral species, including radicals. The model is validated against experimental polarization behavior and chemical degradation under an open circuit voltage (OCV) hold test at $368.15 \mathrm{~K}$. The four-step chemical degradation of a PFSAbased membrane is assumed to start by an attack by hydroxyl radical at the terminal ether bond in the side chain. The source of the attacking hydroxyl radical is an indirect hydrogen peroxide formation and the subsequent decomposition at Fenton's reagent in the membrane. Simulation of degradation rate (defined as the loss of cell voltage with time at a fixed cell operating condition and at a point of time with a known degradation history) under an OCV-hold test agree qualitatively with the degradation rates reported in the literature.

(C) The Author(s) 2018. Published by ECS. This is an open access article distributed under the terms of the Creative Commons Attribution Non-Commercial No Derivatives 4.0 License (CC BY-NC-ND, http://creativecommons.org/licenses/by-nc-nd/4.0/), which permits non-commercial reuse, distribution, and reproduction in any medium, provided the original work is not changed in any way and is properly cited. For permission for commercial reuse, please email: oa@electrochem.org. [DOI: 10.1149/2.0351806jes]
\end{abstract}

(cc) BY-NC-ND

Manuscript submitted December 15, 2017; revised manuscript received April 16, 2018. Published April 27, 2018. This paper is part of the JES Focus Issue on Proton Exchange Membrane Fuel Cell (PEMFC) Durability.

Having achieved acceptable performance levels, polymer electrolyte membrane fuel cells (PEMFCs) are at a juncture where cost and durability are key priorities to achieve full scale commercialization of the technology. Degradation in PEMFCs is typically dominated by the degradation of the membrane ${ }^{1-3}$ due to various mechanisms depending on operating conditions. Degradation in the catalyst layer (CL) can also be dominant as reported for example in a recent study by Schulenburg et al. ${ }^{4}$ where a loss in performance after 1,000 start/stop cycles was attributed to reduced porosity of the CL and concomitant loss in transport properties. The membrane in this study remained virtually unaffected; Pt-coarsening was similar to a case where the PEMFC was subjected to 24,000 voltage-cycles with no notable degradation in performance. The effect of in-plane material anisotropy in gas diffusion layer (GDL) was shown to lead to mechanical instability in the membrane. ${ }^{5}$ Furthermore, catalyst layers and membrane have different mechanical properties and interactions between the two layers are known to have significant impact on the fatigue properties of the composite catalyst coated membrane (CCM) materials with an adverse effect on durability. ${ }^{6}$ A literature survey on long-term durability by de Bruijn et al. ${ }^{7}$ noted that two of the most frequently observed manifestations of degradation are i) loss of water removal efficiency and ii) loss of platinum surface area at the cathode.

Despite the observation of degradation processes away from the membrane, the life-limiting failure of a PEMFC system is mainly due to membrane failures in the form of membrane-thinning, cracks, tears, punctures or pinholes. ${ }^{1,8-10}$ Although membrane degradation in an operating fuel cell is generally caused by a combination of chemical, mechanical and thermal stressors, it is the chemical degradation of the membrane which is at play under open circuit voltage (OCV) when crossover of gaseous reactants is the highest. Fundamentally, an atomistic level understanding of chemical reactions and processes is required to describe the mechanism of the chemical degradation; however, for practical purposes a macroscopic description is more expedient and can be adequate to represent the mechanical and thermal

*Electrochemical Society Member.

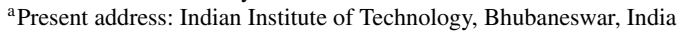

${ }^{\mathrm{z} E-m a i l: n d j i l a l i @ u v i c . c a}$ degradation mechanisms. ${ }^{11}$ Ideally, multiscale models, i.e. macroscopic models informed by microscopic details, can provide a more general and complete representation than simple macroscopic models because they can transfer understanding of atomistic chemical degradation and microscopic physical details to the macroscale. ${ }^{12}$ Multiscale simulations still present challenges and remain computationally expensive. $^{13}$

Progress in understanding ionomer chemical degradation in PEMFCs has been gained from experimental ex-/in-situ testing, monitoring and post-mortem analysis of degraded membranes. In-situ testing aimed at simulating chemical-only degradation of the membrane is carried out at OCV where the reactant gases permeation from one electrode to another is higher than when a net cell current is drawn. A reaction between the crossing over gases leads to the formation of radicals, or a precursor of radicals, such as hydrogen peroxide. Although a typical operating temperature of a PEMFC is $353 \mathrm{~K}$, the presence of $\cdot \mathrm{H}, \cdot \mathrm{OH}$ and $\cdot \mathrm{OOH}$ radicals at the electrodes have been detected at temperatures as low as $300 \mathrm{~K}$ in an operating fuel cell monitored under an electron spin resonator (ESR). ${ }^{14}$ In addition, carbon centered radicals, a product of Nafion degradation, has also been detected after closed circuit operation-with the cathode giving stronger signal than anode. Higher temperatures will exacerbate the concentration and activity of these radicals.

Chemical degradation of the membrane is normally measured by the fluoride emission rate (FER) at each electrode. In-situ OCV testing and modeling has been carried out by several researchers. The relative amount of FER at the electrodes is influenced by factors such as gas stream composition, gas permeation coefficients in the membrane and the location of Pt band formation in the membrane. ${ }^{15}$ OCV hold tests by Ohma et al. ${ }^{15}$ found that the Pt band formed where the electrode potential inside the membrane in the thickness direction changed abruptly; close to $0 \mathrm{~V}$ between anode and the Pt band and close to cathode potential in the rest of the membrane region. The FER from the electrode nearer to the Pt band was found higher leading to the conclusion that membrane degradation is enhanced at the Pt band. In cases where Pt band could not be observed, the total FER over the duration of the test was over 6 times lower with cathode exhibiting about $10 \%$ higher FER over anode. Conversely, Macauley et al. ${ }^{16}$ recently 
provided experimental evidence for the beneficial effects platinum has on reducing overall membrane degradation rates and enhancing the lifetime of a stack under accelerated stress tests.

To date, a few 1D models of membrane degradation that do not resolve the impact of the current collector/channel geometry have been reported in the open literature, and most model the membrane degradation process as a one step process. ${ }^{17-20}$ A limited number of multiscale models have been reported, e.g., ${ }^{21}$ which combined 3D-resolved Coarse-Grained Molecular Dynamics simulating PEM ageing, with 2D kinetic Monte Carlo models resolving the $\mathrm{H}_{2} \mathrm{O}_{2}$ formation in the PEMFC electrodes and 1D modeling of the species transport along the MEA. Considering the very large molecular size as well as the long side chain in Nafion, its chemical degradation cannot possibly be completed in a single step. In fact, recent ex-situ degradation of Nafion under controlled conditions ${ }^{22-24}$ have clearly shown that degradation is a long multi-step process.

The scope of this paper is limited to membrane chemical degradation and its effect on PEMFC performance. A transient chemical degradation model is developed and implemented in a finite element based modeling software, COMSOL Multiphysics 4.3a. The 2D model uses a dynamic mesh to allow accurate representation of membrane thinning due to material loss and of hygrothermal swelling. The 2-D formulation accounts for spatial variations of key variables such as species concentration and current densities, and provides a basis for coupling with ongoing mechanical degradation modeling work where the membrane is subjected to different stresses between the land and channel areas. The details of the chemical degradation pathway is based on a recent experimental study on degradation of a "chemically stabilized" perfluorinated sulfonic acid (PFSA) based polymer membrane in ex-situ Fenton's test. ${ }^{24}$ The role of platinum in the membrane is disregarded; however, an initial uniform iron (II) concentration in the membrane acting as a Fenton's reagent, is assumed. The effect of degradation on steady state performance characteristics of a PEMFC and, vice versa, the influence of an OCV-hold on transient chemical degradation is discussed. The model couples a steady state performance module to a transient chemical degradation module; the coupling is achieved by sharing time/degradation-dependent variables between the modules. Finally, the approach is validated against the experimental OCV hold-test data for chemical degradation as well as polarization behavior of a PEMFC. ${ }^{25}$ The present model builds on the $1 \mathrm{D}$ models of Shah et al., ${ }^{26,27}$ by extending the approach to $2 \mathrm{D}$ and representing membrane chemical degradation with a multi-step kinetic model.

\section{Performance and Crossover-Led Chemical Degradation Models}

The modeling work presented here is comprised of two, macroscopic 2D, isothermal sub-models; 1) a steady-state PEMFC performance and 2) a transient chemical degradation model of the membrane. The former is developed to study the effect of the latter on the fuel cell operating characteristics whereas; the latter along with the former is used to model the chemical degradation as a function of an arbitrary cell operating protocol. PFSA-based polymer membrane such as Nafion is used for the purpose of model development. The molecular structure of Nafion consists of a backbone of polytetrafluroethylene (PTFE) and a pendant ether ketone group with sulfonic acid $\left(-\mathrm{SO}_{3} \mathrm{H}\right)$ end group, attached to the backbone (Fig. 1). Thus, Nafion is a copolymer with comonomers constituted by the perfluorinated vinyl ether and tetrafluoroethylene. Equivalent weight (EW) of Nafion is defined as the dry polymer weight per mole of sulfonic acid. It exhibits a range of 0.80 to $1.50 \mathrm{~kg} / \mathrm{mol}$. The proton conductivity of Nafion arises from the deprotonation of the acid group in the presence of water in vapor or liquid form. ${ }^{28}$

The chemical degradation of the membrane is enabled by 1) the crossover of $\mathrm{H}_{2}$ and $\mathrm{O}_{2}, 2$ ) the reaction between the crossover species generating radical(s) and 3 ) attack of the radicals on polymer. The details of the performance and chemical degradation models are presented next.

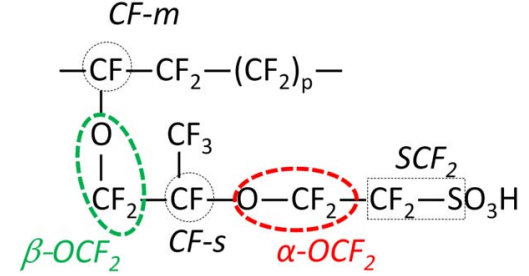

Figure 1. Chemical structure of the PFSA-based membrane Nafion. Structural groups in Nafion enclosed by dotted shapes are identified with a keyword. The model tracks the composition of these groups as a function of degradation. The $\mathrm{EW}$ of the polymer can be expressed as $\mathrm{EW}=50 \mathrm{p}+444$. For $\mathrm{p}=13, \mathrm{EW}=$ 1094; approximate wt\% of the constituent elements are: F (68), C (22), O (7), $\mathrm{S}(3)$ and $\mathrm{H}(0.1)$

$2 D$ performance model.-The steady state, MEA-level performance is based on the conservation of mass, charge and momentum wherever applicable. ${ }^{29}$ Figure 2 shows the geometry of the modeled domain which includes gas diffusion layer (GDL), micro-porous layer (MPL), and CL on each side of the polymer membrane. The left half of the domain is under the land region and experiences a compressive stress of 1.5 MPa. The cell is assumed to operate under high stoichiometry so that the gas concentration along the channel remains approximately the same as at the inlet. In the porous regions encompassing the electrodes, MPLs and the GDLs, the Maxwell-Stefan gas diffusion equations-binary diffusion $\left(\mathrm{H}_{2}-\mathrm{H}_{2} \mathrm{O}\right)$ in the anode-side and ternary $\left(\mathrm{O}_{2}-\mathrm{N}_{2}-\mathrm{H}_{2} \mathrm{O}\right)$ in the cathode-side-were solved. The governing equations in various cell components are listed in Table I. The binary diffusivities were calculated using the expression in Table II and corrected in the porous regions using the Bruggeman relation.

The electrochemical reactions considered are $\left(75^{\circ} \mathrm{C}\right)$ :

Anode and Cathode:

$$
\begin{gathered}
\mathrm{H}_{2} \rightarrow 2 \mathrm{H}^{+}+2 e^{-} \quad E_{H O R, 2 e}^{\circ}=0 \text { vs. SHE } \\
\mathrm{O}_{2}+4 H^{+}+4 e^{-} \rightarrow 2 \mathrm{H}_{2} \mathrm{O} \quad E_{O R R, 4 e}^{\circ}=1.190 \text { vs. SHE}
\end{gathered}
$$

Anode-only:

$$
\mathrm{O}_{2}+2 \mathrm{H}^{+}+2 e^{-} \rightarrow \mathrm{H}_{2} \mathrm{O}_{2} \quad E_{O R R, 2 e}^{\circ}=0.695 \text { vs. SHE }
$$

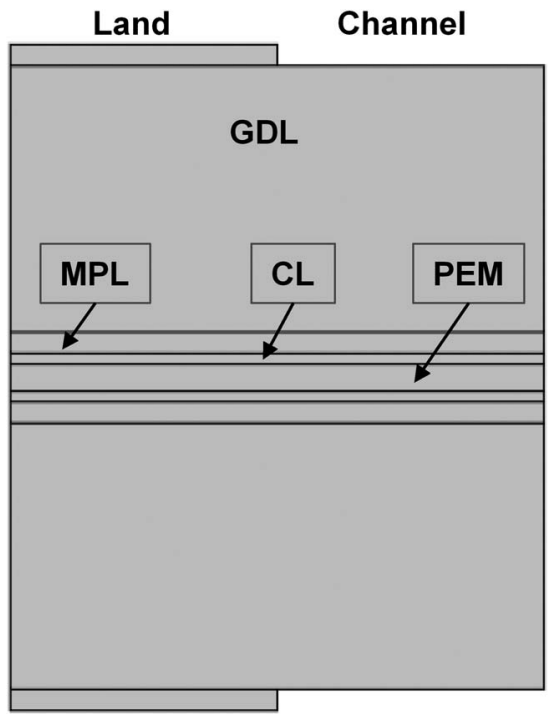

Figure 2. Geometry of the modeled domain. Layered sandwich structure constituted by the CL, MPL and the GDL is symmetric to either side of the membrane. 
Table I. Transport equations modeled in various computational domains.

\begin{tabular}{|c|c|c|}
\hline & Equation & Note \\
\hline \multicolumn{3}{|l|}{ MPL / GDL } \\
\hline & $\nabla \cdot\left(-\epsilon_{\mathrm{s}}^{1.5} \sigma_{s} \nabla \varphi_{s}\right)=0$ & $\begin{array}{l}\epsilon_{s}, \sigma_{s} \text { and } \varphi_{s} \text { are respectively the phase fraction, conductivity and the electric potential of the electron-conducting phase } \\
\text { in the respective domain. }\end{array}$ \\
\hline & $\nabla \cdot\left(-\rho \omega_{i} \sum_{j} \epsilon^{1.5} D_{i j} \nabla x_{j}\right)=0$ & $\begin{array}{l}i=\mathrm{H}_{2} \text { and } \mathrm{H}_{2} \mathrm{O} \text { (anode-side MPL / GDL) } i=\mathrm{O}_{2}, \mathrm{H}_{2} \mathrm{O} \text { and } N_{2} \text { (cathode-side MPL / GDL) } \epsilon \text { is the gas phase } \\
\text { porosity in the respective domain }\end{array}$ \\
\hline \multicolumn{3}{|r|}{ P } \\
\hline & $\nabla \cdot\left(-\epsilon_{-, \mathrm{s}}^{1.5} \sigma_{s} \nabla \varphi_{s}\right)=S_{\varphi, 1}$ & $S_{\varphi, 1}=A_{v}^{-} i_{-}^{r e f}\left(\frac{c_{H_{2}}}{c_{H}^{r e f}}\right)\left(e^{\left(\frac{\alpha_{-}, a F \eta}{R T}\right)}-e^{\left(\frac{-\alpha_{-, c} F \eta}{R T}\right)}\right) \eta=\varphi_{s}-\varphi_{e}-E_{-}^{r e f}$ \\
\hline & $\nabla \cdot\left(-\epsilon_{-, \mathrm{e}}^{1.5} \sigma_{e} \nabla \varphi_{e}\right)=-S_{\varphi, 1}$ & \\
\hline & $\nabla \cdot\left(-\rho \omega_{i} \sum_{j} D_{i j} \nabla x_{j}\right)=\frac{S_{\varphi, 1}}{2 F}$ & $i=\mathrm{H}_{2}$ or $\mathrm{H}_{2} \mathrm{O}$ \\
\hline CI (cathode) & $\nabla \cdot\left(-\epsilon_{-, \mathrm{e}}^{1.5} \mathrm{D}_{\mathrm{e}, \mathrm{O}_{2}} \nabla c_{O_{2}}\right)=\frac{-S_{\varphi, 2}}{2} / F$ & $S_{\varphi, 2}=A_{v}^{-} i_{+, 2 e}^{r e f} c_{O_{2}}\left(c_{H^{+}}\right)^{2} e^{\left(\frac{\alpha_{+}, 2 e F \eta}{R T}\right)} \eta=\varphi_{s}-\varphi_{e}-E_{+, 2 e}^{r e f}$ \\
\hline \multirow{5}{*}{ Membrane } & $\nabla \cdot\left(-\epsilon_{+, \mathrm{s}}^{1.5} \sigma_{s} \nabla \varphi_{s}\right)=S_{\varphi, 3}$ & $S_{\varphi, 3}=A_{v}^{+} i_{+}^{r e f}\left(\frac{c_{O_{2}}}{c_{O_{2}}^{r e f}}\right)\left(e^{\left(\frac{\alpha+, a F \eta}{R T}\right)}-e^{\left(\frac{-\alpha_{+, c} F \eta}{R T}\right)}\right) \eta=\varphi_{s}-\varphi_{e}-E_{+}^{r e f}$ \\
\hline & $\begin{array}{l}\nabla \cdot\left(-\epsilon_{+, \mathrm{e}}^{1.5} \sigma_{e} \nabla \varphi_{e}\right)=-S_{\varphi, 3} \\
\nabla \cdot\left(-\rho \omega_{i} \sum_{j} D_{i j} \nabla x_{j}\right)=\frac{S_{\varphi, 3}}{4 F} \\
\nabla \cdot\left(-\epsilon_{+, \mathrm{e}}^{1.5} \mathrm{D}_{\mathrm{e}, \mathrm{H}_{2}} \nabla c_{H_{2}}\right)=-\frac{S_{\varphi, 2}}{2}\end{array}$ & $\begin{array}{l}i=\mathrm{O}_{2}, \text { and } \mathrm{H}_{2} \mathrm{O} \\
S_{\varphi, 2}=A_{v}^{-} i_{+, 2 e}^{r e f} c_{O_{2}}\left(c_{H^{+}}\right)^{2} e^{\left(\frac{\alpha_{+, 2 e} F \eta}{R T}\right)} \eta=\varphi_{s}-\varphi_{e}-E_{+, 2 e}^{r e f}\end{array}$ \\
\hline & $\nabla \cdot\left(-\sigma_{e} \nabla \varphi_{e}\right)=0$ & \\
\hline & $\nabla \cdot\left(-\phi_{\mathrm{w}}^{1.5} \mathrm{D}_{\mathrm{e}, \mathrm{H}_{2}} \nabla c_{H_{2}}\right)=\nabla \cdot\left(-\phi_{\mathrm{w}}^{1.5} \mathrm{D}_{\mathrm{e}, \mathrm{O}_{2}} \nabla c_{O_{2}}\right)=-\frac{S_{\varphi, 2}}{2}$ & $\begin{array}{l}S_{\varphi, 2}=A_{v}^{-} i_{e, 2 e}^{r e f} c_{O_{2}}\left(c_{H^{+}}\right)^{2} e^{\left(\frac{\alpha_{+, 2 e} F \eta}{R T}\right)} \eta=\varphi_{s, \text { theoretical }}-\varphi_{e}-E_{+, 2 e}^{r e f} \\
\varphi_{s, \text { theoretical }}=0.14 l V ; l=\text { relative distance from anode }- \\
\text { membrane interface }(0 \text { at anode }- \text { membrane interface } ; 1 \text { at anode }- \text { membrane interface })\end{array}$ \\
\hline & $\begin{array}{l}\frac{\partial c_{i}}{\partial t}+\nabla \cdot\left(-\mathrm{D}_{\mathrm{i}} \nabla c_{i}\right)=S_{i} \\
\frac{\partial c_{i}}{\partial t}=R_{i}-c_{i} \frac{\partial\left(\varepsilon_{d}+0.0378 \lambda\right)}{\partial t}\end{array}$ & $\begin{array}{l}i=\mathrm{HF} \text { and } \mathrm{H}_{2} \mathrm{O}_{2} \\
i=\mathrm{SO}_{3}, \mathrm{COOH}, \mathrm{CF}_{2}, \mathrm{OH}, c_{\text {alpha }} \text { and } c_{\text {beta }}\end{array}$ \\
\hline
\end{tabular}


Table II. Expression of binary gas diffusivity and parameters associated with its calculation.

Variable/Parameter

Empirical expression of binary diffusivities ${ }^{50}$

Molar mass of:

Hydrogen

Oxygen

Nitrogen

Water vapor

Diffusion volume of (Fuller et al. ${ }^{50}$ ):

Hydrogen

Oxygen

Nitrogen

Water vapor

Cathode-only:

$\mathrm{C}+2 \mathrm{H}_{2} \mathrm{O} \rightarrow \mathrm{CO}_{2}+4 \mathrm{H}^{+}+4 e^{-} \quad E_{\mathrm{COR}, 4 e}^{\circ}=0.207$ vs. SHE

The kinetic expressions for Reactions 1-4 are given in Table I. The parasitic reactions, electrochemical reduction at anode and oxidation at the cathode, require consideration of the crossover of the reactant gases through the membrane, $\mathrm{H}_{2}$ from anode to cathode and $\mathrm{O}_{2}$ from cathode to anode which is discussed next.

$\mathrm{H}_{2}$ and $\mathrm{O}_{2}$ gas crossover through the membrane.-The transport of $\mathrm{H}_{2}$ across the membrane occurs under the gradient of the hydrogen partial pressure $\left(P_{\mathrm{H}_{2}}\right)$ and the gradient of total pressure across the membrane $(P) .{ }^{30}$ Under pure partial pressure gradient (i.e., $\nabla P=0$ ), the permeability $\left(k_{1, H_{2}}\right)$ seems to be different than the permeability under total pressure gradient $\left(k_{2, H_{2}}\right.$ when $\left.\nabla P_{H_{2}}=0\right)$, indicating either a separate mechanism of $\mathrm{H}_{2}$ gas crossover operating under each condition or, alternatively, dominance of one of the two mechanisms proposed by Mittelsteadt and Liu. ${ }^{31}$ The permeation rate constant of each mechanism is governed by a unique Arrhenius Equation. The two types of permeability based on experimental observation ${ }^{30,32}$ are further assumed to be independent of relative humidity above $75^{\circ} \mathrm{C}$. Thus, the permeation rate of $\mathrm{H}_{2}$ across the membrane, $J_{\mathrm{H}_{2}}\left(\mathrm{~A} . \mathrm{m}^{-2}\right)$ can be described as follows:

$$
J_{H_{2}}=k_{1, H_{2}} \nabla P_{H_{2}}+k_{2, H_{2}} \nabla P
$$

The $\mathrm{H}_{2}$ crossover fluxes induced by the two driving forces are assumed not to influence each other. The local concentration of the dissolved $\mathrm{H}_{2}, c_{H_{2}}$ in the membrane is given by Henry's law and is equal to $H_{H_{2}}\left(P_{H_{2}}+\left(P-P_{\text {cathode }}\right)\right)$.

Likewise the permeation kinetics of oxygen is governed by:

$$
J_{O_{2}}=k_{1, O_{2}} \nabla P_{O_{2}}+k_{2, O_{2}} \nabla P
$$

where, $k_{1, O_{2}}\left(\mathrm{~m}^{2} \mathrm{~V}^{-1} \mathrm{~s}^{-1}\right)$ is the permeability coefficient given by the expression $1.54 \times 10^{-5} \times \mathrm{e}^{-2755 / \mathrm{T}} .33$ The oxygen permeation under a gradient of total pressure across the membrane is assumed zero $\left(k_{2, O_{2}}=0\right)$. An RH-dependent model for the oxygen permeation was used by Sethuraman et al. ${ }^{34}$ However, like the case for the hydrogen permeation, we assume that the effect of humidity on the oxygen permeability is minimum and we shall use the recent data by Zhang et al. ${ }^{33}$

Radical generation and chemical degradation of PFSA.-The presence of $\mathrm{H}_{2} \mathrm{O}_{2}$ in the fuel cell membrane has been experimentally confirmed. ${ }^{35} \mathrm{H}_{2} \mathrm{O}_{2}$ can be generated by the chemical reaction of the crossover species or by the electro-chemical $2 \mathrm{e}^{-}$reduction of crossover oxygen at the anode. The anode potential, as discussed in the preceding section, favors the electrochemical route of $\mathrm{H}_{2} \mathrm{O}_{2}$ production which especially dominates under open circuit voltage conditions due to the high crossover rate. The $\mathrm{H}_{2} \mathrm{O}_{2}$ produced at the anode has a boiling point $\left(150.2^{\circ} \mathrm{C}\right)$ higher than water and joins the dissolved
Symbol

Expression/Value

$3.2042 \times 10^{-4} \frac{T^{1.75} \sqrt{\frac{1}{M_{i}}+\frac{1}{M_{j}}}}{P\left(v_{i}^{\frac{1}{3}}+v_{j}^{\frac{1}{3}}\right)}$

$0.002\left(\mathrm{~kg} \mathrm{~mol}^{-1}\right)$

$0.032\left(\mathrm{~kg} \mathrm{~mol}^{-1}\right)$

$0.028\left(\mathrm{~kg} \mathrm{~mol}^{-1}\right)$

$0.018\left(\mathrm{~kg} \mathrm{~mol}^{-1}\right)$

7.07

16.6

17.9

12.7

water in the polymer and diffuses through the membrane. The diffusing $\mathrm{H}_{2} \mathrm{O}_{2}$ decomposes at Fenton reagents such as iron, ${ }^{36}$ which are apparently present in the membrane in the range of $\left[\mathrm{mol} / \mathrm{m}^{3}\right]$, and generate hydroxyl radicals as:

$$
\mathrm{Fe}^{2+}+\mathrm{H}_{2} \mathrm{O}_{2} \rightarrow \mathrm{Fe}^{3+}+\mathrm{OH}^{-}+\left({ }^{\bullet} \mathrm{OH}\right)
$$

Iron in the oxidation state three does not catalyze peroxide decomposition. Under a reducing environment $\mathrm{Fe}^{2+}$ is regenerated from $\mathrm{Fe}^{3+}$ as follows:

$$
\mathrm{Fe}^{3+}+{ }^{\bullet} \mathrm{H} \rightarrow \mathrm{Fe}^{2+}+\mathrm{H}^{+}
$$

A dynamic equilibrium between $\mathrm{Fe}^{2+}$ and $\mathrm{Fe}^{3+}$ exists. The highly oxidative hydroxyl $(. \mathrm{OH})$ radical is generally believed to attack the oxygen containing weak links such as the oxygen linking the side group to the main chain or the $-\mathrm{COOH}$ end group on the main chain. Chemically stabilized grade of the PFSA-based membranes such as Nafion 211 possesses negligibly small quantity of oxygen containing main chain terminal group/s. Thus the chemical degradation of such membranes is initiated at the weakest ether link on the side chain, as evidenced in a recent ex-situ Fenton's test ${ }^{24}$ and is assumed as such in this paper. The study by Ghassemzadeh \& Holdcroft ${ }^{24}$ on Nafion 211 further indicates that the $\alpha-\mathrm{OCF}_{2}$ is the first chemical group under attack by the hydroxyl radical. This is likely followed by the attack on the $\beta-\mathrm{OCF}_{2}$ which was reported to occur after a time lag of over $24 \mathrm{~h}$, while the concentrations of either of the main chain groups, $\mathrm{CF}-\mathrm{m}$ and $\mathrm{CF}_{2}$, remained unchanged even after $48 \mathrm{~h}$ of test signifying little or no degradation of the main chain.

Based on the above, the pathway for the chemical degradation of the membrane in an operating fuel cell is defined by the four sequential irreversible chemical reactions, ${ }^{37}$ shown in Fig. 3. The rate constants and reaction rates for reactions (i) to (iv) in Fig. 3 and for the reaction in Eq. 7 are listed in Table III. The longer the $-\left(\mathrm{CF}_{2}\right)_{\mathrm{p}} \mathrm{COOH}$ molecule (i.e., higher value of $p$ ) in reaction (iv) in Fig. 3, the more susceptible it could be to attack by ${ }^{\bullet} \mathrm{OH}$ radical. ${ }^{38}$ In this work the rate constant for all the sequential reactions in Fig. 3 will be assumed constant and independent of the chain length. The chemical species $\mathrm{SCF}_{2}$, $\alpha-\mathrm{OCF}_{2}, \beta-\mathrm{OCF}_{2}, \mathrm{CF}_{2}$, and $\mathrm{COOH}$ are always part of the polymer chain which is modeled as rigid. The species $\mathrm{COOH}$ refer to the $\mathrm{COOH}$ group attached to the main chain, cf. Eq. (iii) and (iv) in Fig. 3 , and does not represent the $\left(-\left(\mathrm{CF}_{2}\right)_{\mathrm{x}}-\right)$ group. Relative position of various functional groups with respect to the repeating unit of Nafion is depicted in Fig 1.

The dry density, $\rho_{d r y}$, and the EW of Nafion are related as: ${ }^{37}$

$$
\rho_{d r y}=\sum_{i} c_{i} \cdot M_{i} ; E W=\rho_{d r y} / c_{S C F_{2}}
$$

where $c_{i}$ and $M_{i}$ are respectively the concentration and molecular weight of species $i\left(i=\mathrm{SCF}_{2}, \alpha-\mathrm{OCF}_{2}, \beta-\mathrm{OCF}_{2}, \mathrm{CF}_{2}\right.$, and $\left.\mathrm{COOH}\right)$.

Incorporation of the preceding elements in the degradation model requires the following assumptions: 


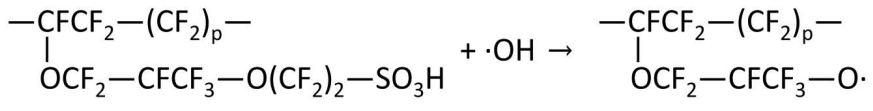

$$
\begin{aligned}
& -\mathrm{CFCF}_{2}-\left(\mathrm{CF}_{2}\right)_{\mathrm{p}}- \\
& \quad \mathrm{l}+3(\cdot \mathrm{OH}) \rightarrow-(\mathrm{O} \cdot) \mathrm{CFCF}_{2}-\left(\mathrm{CF}_{2}\right)_{\mathrm{p}}-+6 \mathrm{HF} \\
& \mathrm{OCF}_{2}-\mathrm{CFCF}_{3}-\mathrm{O} .
\end{aligned}
$$$$
-\left(\mathrm{O} \cdot \mathrm{CFCF}_{2}-\left(\mathrm{CF}_{2}\right)_{\mathrm{p}}-+\cdot \mathrm{OH} \rightarrow 2-\left(\mathrm{CF}_{2}\right)_{\mathrm{p} / 2} \mathrm{COOH}+3 \mathrm{HF}\right.
$$

\author{
Figure 3. Pathway for the $\cdot \mathrm{OH}$-mediated irreversible chemical \\ degradation of PFSA membrane.
}

$-\left(\mathrm{CF}_{2}\right)_{\mathrm{p}} \mathrm{COOH}+2(\cdot \mathrm{OH}) \rightarrow-\left(\mathrm{CF}_{2}\right)_{\mathrm{p}-1} \mathrm{COOH}+2 \mathrm{HF}$
1. There is no oxygen containing end groups on the main chain at beginning of life (BOL). Hydrogen ion concentration or the $\mathrm{pH}$ of the membrane does not change with the degradation.

2. The reaction order with respect to each reacting chemical species is one except for Eq. 8 where the reaction order with respect to $\cdot \mathrm{H}$ is assumed zero. All of the degradation reactions in Fig. 3 are irreversible.

3. The chemical species $\mathrm{SCF}_{2}, \alpha-\mathrm{OCF}_{2}, \beta-\mathrm{OCF}_{2}, \mathrm{CF}_{2}$, and $\mathrm{COOH}$ are always part of the polymer chain. These species participate in degradation reactions but do not diffuse as they are chemically bonded to the main chain. Hydroxyl radical is another of the species for which diffusion is not considered due to its highly reactive and unstable nature. Its composition is determined by its production via Fenton reaction and its reaction in degradation reactions (Fig 3). All of the fluorine leaves the system as HF species. The remaining chemical species (containing $\mathrm{C}$ and $\mathrm{S}$ ) are washed out and their effect is accounted for in characteristics such as EW, of degraded Nafion.

4. The loss of species $\mathrm{COOH}$ (reaction (iv) in Fig. 3) is not allowed when $c_{\mathrm{CF}_{2}}$ is greater than $c_{\mathrm{COOH}}$.

5. The water uptake and associated swelling characteristics of the membrane is unchanged by the degradation.

6. There is no degradation in PEMFC components other than the membrane.

The process of chemical degradation alters the material characteristics of Nafion slowly but continuously. A relation between these material characteristics and the polymer composition is needed to study the effect of chemical degradation of the membrane on cell performance.

The porosity of the membrane, $\phi_{w}$, is calculated as volume fraction of the membrane occupied by the liquid water, given by:

$$
\phi_{w}=\frac{\lambda V_{w}}{\lambda V_{w}+V_{m}}
$$

where $\lambda$ is the membrane water content defined as the number of water molecules per mole of charge site concentration and $V_{w}$ and $V_{m}$ are the molar volume of the water and the membrane respectively. The material loss originating from the degradation effects a dimensional change modeled as an equivalent volumetric strain, $\varepsilon_{d}$ :

$$
\varepsilon_{d}=\frac{V_{m} C_{S C F_{2}}}{V_{m}^{0} c_{S C F_{2}}^{0}}-1
$$

where $V_{m}^{0}$ and $c_{S C F_{2}}^{0}$ are the molar volume and the charge site concentration of the membrane at BOL. In addition, the membrane experiences a volumetric strain, $0.0256 \lambda$, induced by the liquid water uptake.

The time-dependent mass conservation of non-diffusing species, $i,\left(i=\mathrm{SCF}_{2}, \alpha-\mathrm{OCF}_{2}, \beta-\mathrm{OCF}_{2}, \mathrm{CF}_{2}, \mathrm{OH}\right.$ and $\left.\mathrm{COOH}\right)$ is governed by:

$$
\frac{\partial c_{i}}{\partial t}=R_{i}-c_{i} \frac{\partial\left(\varepsilon_{d}+0.0256 \lambda\right)}{\partial t}
$$

where $R_{i}$ is the source term of species $i$, expressed in terms of reaction rates and stoichiometry of reactions in Table IV. The second term on the RHS of Eq. 12 takes into account the diluting/concentrating effects arising from membrane swelling and material loss.

Coupling transient chemical degradation and the $2 D$ performance models. - The performance characteristics of a PEMFC under normal operating conditions are fairly stable and, within limits, independent of cell degradation processes at a short time scale of an hour. Thus, the performance of the cell is modeled assuming steady state operation of the cell. However, we note that transient effects arising from chemical degradation of the membrane can influence the performance characteristics by altering the degradation dependent parameters such as membrane porosity and conductivity which are inputs to the performance model. In Ref. 21, a feedback between the degradation mechanisms and the performance was taken into account, allowing the model to predict the cell voltage decay, including the OCV one. The present approach is consistent with concepts presented in Refs. 19,39 .

The ageing processes linked to chemical degradation of the membrane are considered to be a function of time and field variables relevant to steady-state performance. The coupling of the performance and the chemical degradation models is relatively straightforward wherein the transient physico-chemical processes governing chemical degradation of the membrane are solved together with the steady state processes. The models and their coupling is validated against recently published experimental accelerated stress test data (chemical degradation and performance). ${ }^{25}$

Boundary and initial conditions.-The boundary conditions are summarized in Table VI. The inlet hydrogen, oxygen, and water vapor concentrations are calculated according to the operating conditions presented in Lim et al. ${ }^{25}$ Hydrogen peroxide and hydrogen fluoride

Table III. Reaction rates and reaction constants for reactions (i) to (iv) in Fig. 3 and Fenton reactions.

\begin{tabular}{lll} 
Reaction & Rate constant (identifier) & Reaction rate (identifier) \\
\hline (i) in Fig. 3 & $2.35 \times 10^{3} \mathrm{~m}^{3} / \mathrm{mol} / \mathrm{s}\left(\mathrm{k}_{1}\right)^{51}$ & $k_{1} \cdot c_{S C F_{2}} \cdot c_{O H}\left(r_{1}\right)$ \\
(ii) in Fig. 3 & $9.04 \times 10^{3} \mathrm{~m}^{3} / \mathrm{mol} / \mathrm{s}\left(\mathrm{k}_{2}\right)$ & $k_{2} \cdot c_{\alpha-O C F_{2}} \cdot c_{O H}\left(r_{2}\right)$ \\
(iii) in Fig. 3 & $8.5 \times 10^{4} \mathrm{~m}^{3} / \mathrm{mol} / \mathrm{s}\left(\mathrm{k}_{3}\right)$ & $k_{3} \cdot c_{\beta-O C F_{2}} \cdot c_{O H}\left(r_{3}\right)$ \\
(iv) in Fig. 3 & $1.0 \times 10^{3} \mathrm{~m}^{3} / \mathrm{mol} / \mathrm{s}\left(\mathrm{k}_{4}\right)^{52} 1.02 \times 10^{5} \mathrm{~m}^{3} / \mathrm{mol} / \mathrm{s}^{38}$ & $k_{4} \cdot c_{C O O H} \cdot c_{O H}\left(r_{4}\right)$ \\
Eq. 7 & $1.05 \times 10^{5} \mathrm{exp}(-35397 / \mathrm{R} / \mathrm{T}) \mathrm{m}^{3} / \mathrm{mol} / \mathrm{s}\left(\mathrm{k}_{5}\right)$ & $k_{5} \cdot c_{F_{e}} \cdot c_{O H}\left(r_{5}\right)$ \\
Eq. 8 & $0.3 \mathrm{~s}^{-1}\left(\mathrm{k}_{6}\right)$ & $\mathrm{k}_{6} \cdot c_{F_{e}}{ }^{3+} ; c_{F_{e}}{ }^{3+}$ is the concentration of iron (III) in the membrane
\end{tabular}


Table IV. Source terms for the chemical species $\mathrm{SCF}_{2}, \alpha-\mathrm{OCF}_{2}, \beta-\mathrm{OCF}_{2}, \mathrm{CF}_{2}, \mathrm{OH}$ and $\mathrm{COOH}$ in the membrane.

\begin{tabular}{cccccccc} 
Chemical species $(i)$ & $\mathrm{SCF}_{2}$ & $\alpha-\mathrm{OCF}_{2}$ & $\beta-\mathrm{OCF}_{2}$ & $\mathrm{CF}_{2}$ & $\mathrm{OH}$ & $\mathrm{COOH}$ & $\mathrm{H}_{2} \mathrm{O}_{2}$ \\
\hline Source term $\left(R_{i}+c_{i} \frac{\partial\left(\varepsilon_{d}+0.0378 \lambda\right)}{\partial t}\right)$ & $-r_{1}$ & $r_{1}-r_{2}$ & $r_{2}-r_{3}$ & $14 r_{3}-r_{4}$ & $-r_{1}-3 r_{2}-r_{3}-2 r_{4}+r_{5}$ & $2 r_{3}-H\left(c_{C O O H}-c_{C H_{2}}\right) r_{4} *$ & $-r_{5}$
\end{tabular}

${ }^{*} \mathrm{H}(\mathrm{x})$ is Heaviside function taking a value of 0 for $\mathrm{x}<0$ and 1 for $\mathrm{x}>0$.

Table V. The cell operating parameters to simulate the degradation under OCV hold test.

\begin{tabular}{ll} 
Parameter & Value \\
\hline Cell current & 0 A (open circuit) \\
Relative humidity & $56 \%$ \\
Inlet $\mathrm{O}_{2}$ mass fraction & $40 \%$ \\
Inlet anode pressure & $2.28 \mathrm{~atm}$ \\
Inlet cathode pressure & $2.07 \mathrm{~atm}$ \\
Cell temperature & $368.15 \mathrm{~K}$
\end{tabular}

concentrations are assumed to be zero at the CL and MPL interfaces. For the remaining ionomer species that participate in the membrane degradation, no boundary conditions but initial conditions are required, given these species are fixed inside the membrane. The initial concentrations are:

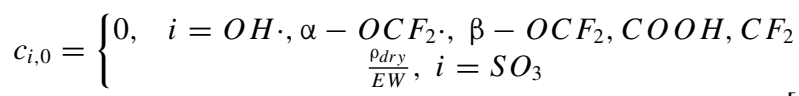

Mesh sensitivity simulations performed with both an extremely fine mesh (24,346 elements) and a fine mesh (6,438 elements) yielded virtually identical results. The results presented here were obtained with the extremely fine mesh. A Massively Parallel Sparse direct Solver (MUMPS) was employed to solve the set of fully coupled equations. Initial conditions for the domains were set as shown in Table V, and initial concentrations were prescribed for all gas species. Typical computational time on a workstation with AMD FX 8-core processors ranged from 15 to $60 \mathrm{~min}$ depending on the operating conditions.

\section{Results and Discussion}

Validation.-The beginning of life (BOL) average polarization behavior over a five-cell stack is compared with the simulated polarization curve in Fig. 4. The simulated open circuit voltage (OCV) of $0.98 \mathrm{~V}$ was lower than the theoretical OCV of $1.16 \mathrm{~V}$ at a cell temperature of $348.15 \mathrm{~K}$. The drop in the OCV was fully accounted for by the hydrogen crossover from anode to cathode which results in parasitic hydrogen oxidation and oxygen reduction reaction at the cathode. Overall, the BOL polarization behavior of the cell is captured quite well by the steady state performance model which contains only two adjustable parameter (exchange current density and transfer coefficient).

Apart from the steady-state performance the transient degradation model was validated against the membrane degradation measured by

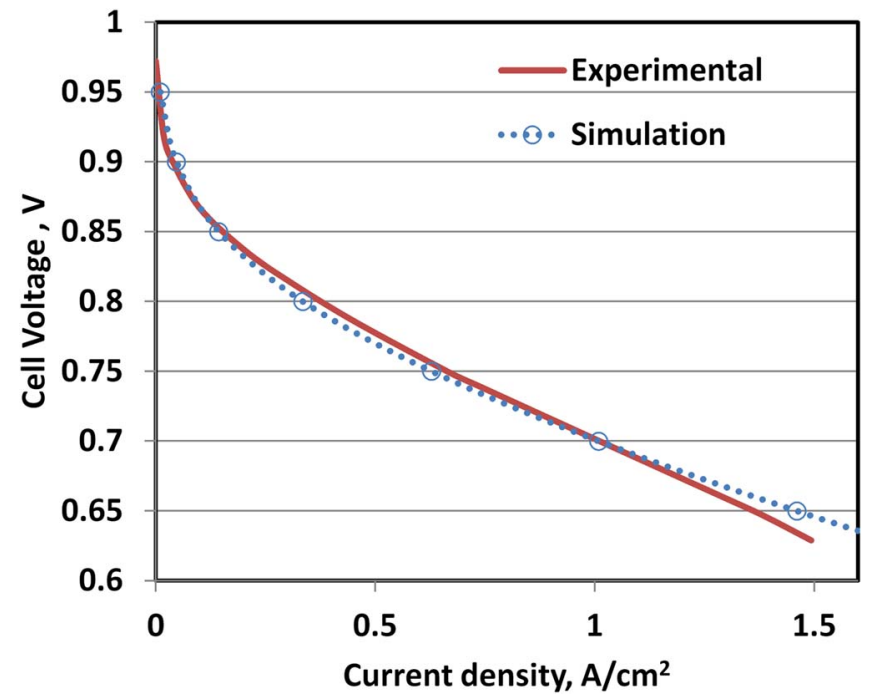

Figure 4. Validation of the steady-state performance model against the average polarization behavior measured over a five-cell stack. The cell temperature, total gas pressure and R.H. at both electrodes were $348.15 \mathrm{~K}, 2 \mathrm{~atm}$ and $100 \%$.

the fluoride emission rate under an OCV hold test described in Lim et al. ${ }^{25}$ The cell operating parameters for the $10 \mathrm{~h}$ OCV hold test as well as the simulation are listed in Table V. The simulated FER reproduces the experimental trend well, but as shown in Figure 5 the experimental FER lags behind the simulation; this is attributed to the extra diffusion path from the membrane-CL interface, where the simulated FER were calculated, to the fluoride detector located downstream along the exhaust stream.

Degradation mechanism.-The ratio of the cathode to anode FER was 1.075 in the simulation vs. 1.15 in the experiment. The simulated ratio of the FER increases with a decrease in the gradient of the theoretical electrode potential in the membrane which was increased linearly from $5 \mathrm{mV}$ at anode-membrane interface to $20 \mathrm{mV}$ at the cathode-membrane interface. Although a further reduction of the gradient in the theoretical electrode potential in the membrane would have resulted in a larger FER ratio, the resulting potential profile would become inconsistent with the experimental profiles observed by Liu \& Zuckerbrod. ${ }^{35}$

The theoretical electrode potential in the membrane is influenced by the size of Pt particles which gets dissolved at the cathode, trans-

Table VI. Summary of the boundary conditions applied in the simulations.

\begin{tabular}{|c|c|c|c|c|c|c|c|}
\hline Variables & $\begin{array}{l}\text { Cathode } \\
\text { GC|GDL }\end{array}$ & $\begin{array}{l}\text { Cathode } \\
\text { GDL|MPL }\end{array}$ & $\begin{array}{l}\text { Cathode } \\
\text { MPL|CL }\end{array}$ & $\begin{array}{l}\text { Cathode CL } \mid \text { Membrane } \\
\& \text { Membrane|Anode CL }\end{array}$ & $\begin{array}{c}\text { Anode } \\
\text { MPL|CL }\end{array}$ & $\begin{array}{l}\text { Anode } \\
\text { GDL|MPL }\end{array}$ & $\begin{array}{c}\text { Anode } \\
\text { GC|GDL }\end{array}$ \\
\hline$c_{O 2, g}$ & continuous & continuous & continuous & No Flux & continuous & continuous & continuous \\
\hline$c_{H 2, g}$ & continuous & continuous & continuous & No Flux & continuous & continuous & continuous \\
\hline & & & No flux & continuous & No flux & & \\
\hline$c_{\mathrm{H}_{2} \mathrm{O}_{2}}$ & & & No flux & continuous & No flux & & \\
\hline $\begin{array}{l}c_{H F} \\
V_{S}\end{array}$ & No flux & continuous & $\begin{array}{l}\text { No flux } \\
\text { continuous }\end{array}$ & continuous & $\begin{array}{l}\text { No flux } \\
\text { continuous }\end{array}$ & continuous & 0 \\
\hline
\end{tabular}




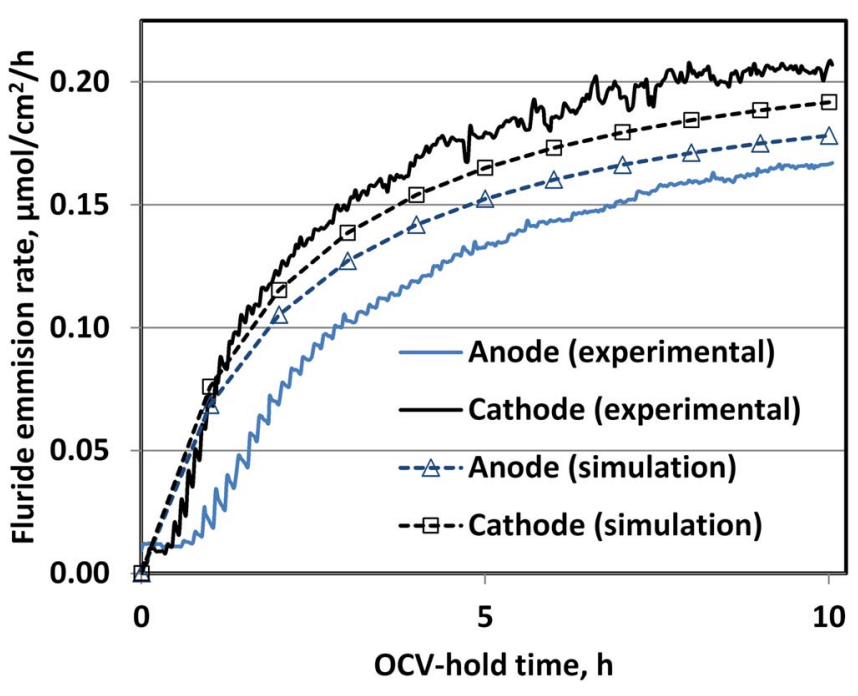

Figure 5. Fluoride emission rate at each electrode during an OCV hold condition (see Table V).

ported and re-deposited in the membrane. ${ }^{40}$ The measured and model potential profile varied approximately linearly from anode up to about $80 \%$ of the membrane thickness. To keep the model complexity in check and ensure tractable simulations, the potential was assumed to vary linearly inside the membrane. The potential profile and the gas composition in the membrane determine the rate of the two-electron reduction of dissolved oxygen to hydrogen peroxide by controlling the overpotential for the electrochemical reactions. The selectivity of peroxide formation over water generation is taken as unity, although it has been shown to generally vary as a function of the electrode potential and humidity. ${ }^{34}$

Formation of radicals from $\mathrm{H}_{2} \mathrm{O}_{2}$ decomposition is not a dominant membrane degradation mechanism in PEMFCs, rather membranedegrading species appear to form in a reaction between molecular $\mathrm{H}_{2}$ and $\mathrm{O}_{2}$ on a catalytic site. ${ }^{41}$ Although a potential dependent $\mathrm{H}_{2} \mathrm{O}_{2}$ mediated indirect route of radical formation at Fenton's regents in the membrane was assumed here, the direct formation of membraneattacking species cannot be ruled out. Thus, there is a need to delineate the role and selectivity of a potential-independent direct and a potential-dependent indirect route of radical formation.

Manifestations of degradation.-Two of the consequences of membrane degradation are membrane thinning and OCV decay (Fig. 6). The OCV decrease resulting from the chemical membrane degradation induced by the OCV-hold test, is more rapidly in the experiments than in the simulation. Although not shown here, most of the decrease in the OCV was recoverable. A similar behavior was observed in another study where a voltage decay during $100 \mathrm{~h}$ of OCV hold was fully recoverable ${ }^{42}$ after treatment to remove contaminating species at electrodes. Hence the rapid and reversible decay in the experimentally-measured OCV can be traced to electrode contamination. The small OCV decay in the simulation is irreversible and due to high gas crossover associated with membrane thinning. A further source of voltage decay is loss of electrochemical surface area which is outside the scope of this study. The high frequency impedance yields an almost constant conductivity value $\left(\sim 0.2 \Omega \cdot \mathrm{cm}^{2}\right)$ in the steady OCV phase from BOL to EOL, likely due to counteracting effects of reduced proton conductivity and membrane thinning.

Without the addition of radical scavengers or additives such as ceria, ${ }^{43,44}$ PFSA based membrane does not seem to stabilize chemically and structurally. When subjected to harsh conditions such as high temperature OCV-hold, these membranes start to degrade chemically. Figure 7 shows the evolution of the simulated concentration of various functional groups of Nafion during the $10 \mathrm{~h} \mathrm{OCV}$-hold test. The most notable observation is the fact that $15.66 \%$ of sulfonic

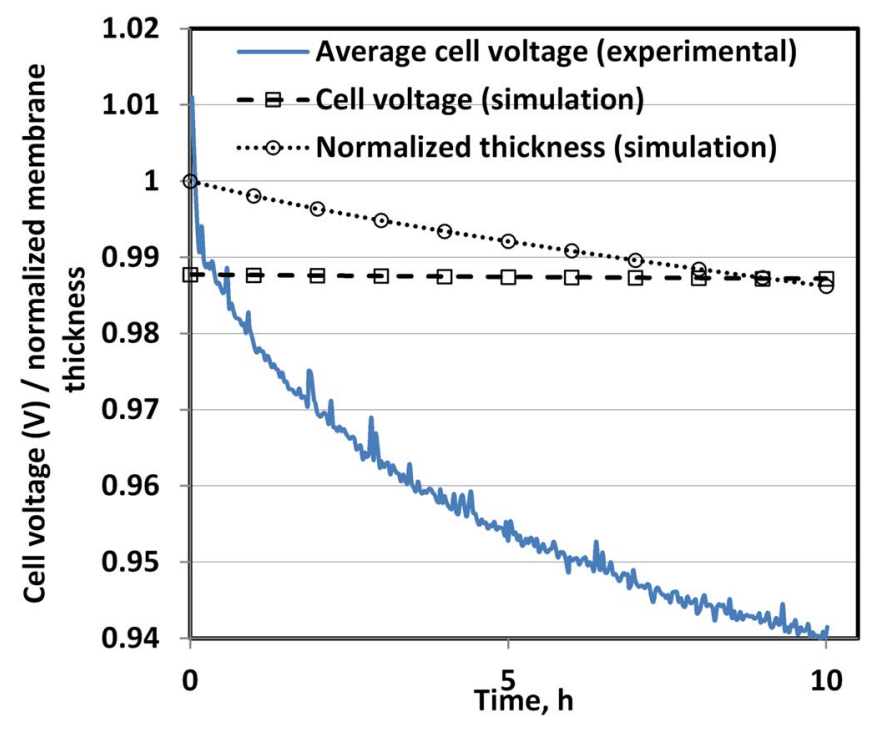

Figure 6. Open circuit voltage and normalized membrane thickness during the OCV-hold test for $10 \mathrm{~h}$.

acid head groups are lost over the $10 \mathrm{~h}$ period of OCV-hold test with only $1.4 \%$ reduction in thickness; whereas as noted above protonic conductivity remains essentially constant. Lim et al. surmised this is due to a counteracting effect of membrane thinning and a decrease in the membrane conductivity due to the loss of the sulfonic acid head groups. Conversely, considering negligible membrane thinning, it could be argued that some side chain fragments are not actually washed away and stay inside the membrane with intact sulfonic acid head groups. This is especially plausible given that the C-S bond in the sulfonic acid group is not the weakest group to be attacked by the radicals, whereas the two $\mathrm{C}-\mathrm{O}-\mathrm{C}$ ether bonds on the side chain are more susceptible to radical attack.

After OCV-hold for $10 \mathrm{~h}$, the measured cell polarization behavior shows a marked decrease especially in the activation regime (Fig. 8). The trend is captured in the simulated polarization behavior; however, the small loss in cell performance in the activation regime is not reproduced by the simulation. The activation loss in the measured cell polarization behavior could be due to loss of cathode catalytic activity. The present model does not account for any CL degradation

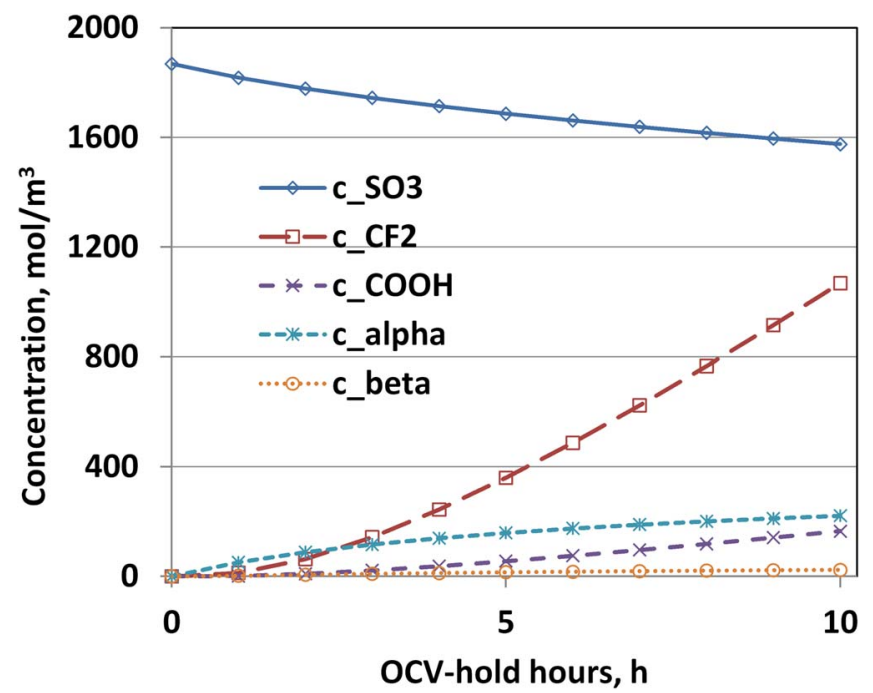

Figure 7. Evolution of the concentration of various chemical groups during the OCV-hold test for $10 \mathrm{~h}$. 


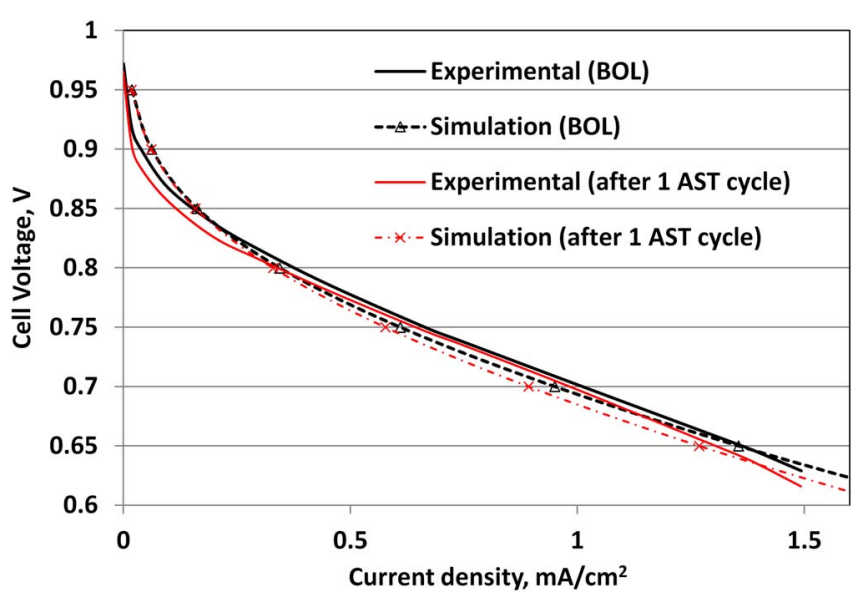

Figure 8. The polarization behavior of the cell (experimental data is the mean over a five cell stack) at $348.15 \mathrm{~K}$ and $100 \%$ relative humidity at beginning of life and after an OCV-hold of $10 \mathrm{~h}$.

such as possible CL poisoning by the product of the degradation (e.g., the (bi-) sulfate ion) or for loss in catalytic activity due to $\mathrm{Pt}$ coarsening, dissolution and re-deposition in the membrane. Ongoing work is aimed at incorporating CL degradation in the model.

Experimental observations point to the complex interplay and equilibrium among various radicals $\left({ }^{\bullet} \mathrm{H},{ }^{\bullet} \mathrm{OH},{ }^{\bullet} \mathrm{OOH}\right.$ etc. $)$ and this should also be considered in further model developments. The chemical degradation mechanism appears to be a function of the dominant radical in the membrane. Recent observations of ex-situ exposure of Nafion to selective ${ }^{\bullet} \mathrm{H}$ and ${ }^{\bullet} \mathrm{OH}$ radicals created by $\beta$-irradiation indicate that the radical ${ }^{\bullet} \mathrm{H}$ attacks both main and side chain $\mathrm{CF}$ bonds, whereas ${ }^{\bullet} \mathrm{OH}$ radical only attacks the oxygen containing ether bond in the side chain of Nafion. ${ }^{23}$ The former mechanism (attack of ${ }^{\bullet} \mathrm{H}$ on the $\mathrm{CF}$ group) results in lower fluoride emission, however, attack by the ${ }^{\bullet} \mathrm{OH}$ radical results in higher fluoride emission rate. Irrespective of the above mechanism the decrease in conductivity and ion exchange capacity are commensurate with the loss of sulfonic acid group. The deterioration in mechanical properties such as a decrease in strain-tofailure, increase in Young's modulus and a decrease in the ultimate tensile strength are linked to structure of Nafion. In order to predict the performance degradation under combined chemical and mechanical stressors, the gaps in understanding of the interplay between chemical composition, Nafion morphology and mechanical properties need to be bridged. ${ }^{45,46}$

\section{Summary and Outlook}

A transient, isothermal, 2D model of chemical degradation of a polymeric membrane in a PEMFC is developed. Membrane degradation was modeled to proceed in two stages: 1) indirect formation of hydroxyl radical and 2) a four-step attack of hydroxyl radical at the terminal ether bond on the side chain, the ether bond close to the main chain, chain scission at the side chain and chain unzipping. The MEA-level model was validated against the polarization behavior of a five-cell stack at beginning of life as well as after degradation of the stack over $10 \mathrm{~h}$ of OCV-hold testing. The fluoride emission rate, voltage decay and change in membrane thickness under OCV hold test agree qualitatively with the degradation rates recently reported in the literature. The salient insights are:

1. The lower OCV of $0.985 \mathrm{~V}$ compared to the value of $1.16 \mathrm{~V}$ is due to the parasitic electrochemical reactions happening at the cathode, enabled by the hydrogen crossover from anode to cathode.

2. A four-step chemical degradation of the membrane set off by a peroxide-cum-hydroxyl radical formation at the electrode and in the membrane under the presence of a Fenton's reagent suffices to predict the qualitative trend observed in ex-situ Fenton tests and the OCV-hold test in an accelerated stress test.

3. A dynamic equilibrium seems to exist between various radicals such as ${ }^{\bullet} \mathrm{H},{ }^{\bullet} \mathrm{OH}$ and ${ }^{\bullet} \mathrm{OOH}$ in a fuel cell. Efforts to further elucidate the degradation scheme for the chemical degradation and the complex equilibrium and interaction with Nafion are highly warranted. In this respect, recent ex-situ durability tests ${ }^{23}$ subjecting Nafion selectively to a particular radical could prove very valuable.

The reliability of degradation predictions requires more definitive determination of the exact mechanisms governing degradation. One way forward is the use of ab-initio simulations to determine the likelihood or not of various reaction steps. Further developments to improve quantitative fit to experimental degradation rate should also focus on 1) extending the current model to non-isothermal case, 2) implementing recent advances in rapidly evolving pore scale modeling to compute the effective transport parameters of the catalyst layer, MPL and diffusion media, ${ }^{47-49} 3$ ) incorporating the effect of mechanical stressors on the degradation especially its coupling with the chemical degradation, and 4) accounting for the coupling of membrane degradation with other cell components, the CL in particular.

\section{Acknowledgment}

Funding for this research provided by Ballard Power Systems, Automotive Partnership Canada (APC), and the University of Victoria is gratefully acknowledged. PCS acknowledges the financial support, in part, from National Natural Science Foundation of China (2017YFB0102700, 21776226), Hubei 100 Talents Plan, China, and the Hanse-Wissenschaftskolleg, Germany. The authors thank Dr Lim Chan of Simon Fraser University and colleagues at Ballard for valuable discussions and advice.

\section{ORCID}

E. Kjeang (D) https://orcid.org/0000-0002-1373-5212

N. Djilali (1) https://orcid.org/0000-0002-9047-0289

\section{References}

1. R. Borup, J. Meyers, B. Pivovar, Y. S. Kim, R. Mukundan, N. Garland, D. Myers, M. Wilson, F. Garzon, D. Wood, P. Zelenay, K. More, K. Stroh, T. Zawodzinski, J. Boncella, J. E. McGrath, M. Inaba, K. Miyatake, M. Hori, K. Ota, Z. Ogumi, S. Miyata, A. Nishikata, Z. Siroma, Y. Uchimoto, K. Yasuda, K. I. Kimijima, and N. Iwashita, "Scientific aspects of polymer electrolyte fuel cell durability and degradation," Chem. Rev., 107, 3904 (2007)

2. A. P. Young, J. Stumper, S. Knights, and E. Gyenge, "Ionomer Degradation in Polymer Electrolyte Membrane Fuel Cells," J. Electrochem. Soc., 157, B425 (2010).

3. A. A. Shah, K. H. Luo, T. R. Ralph, and F. C. Walsh, Recent trends and developments in polymer electrolyte membrane fuel cell modelling," Electrochim. Acta., 56, 3731 (2011).

4. H. Schulenburg, B. Schwanitz, N. Linse, G. Scherer, and A. Wokaun, "F. Polytechnique, 3D Imaging of Catalyst Support Corrosion in Polymer Electrolyte Fuel Cells b b," J. Phys. Chem. C., 115, 14236 (2011).

5. K. K. Poornesh, Y. J. Sohn, G. G. Park, and T. H. Yang, "Gas-diffusion layer's structural anisotropy induced localized instability of nafion membrane in polymer electrolyte fuel cell," Int. J. Hydrogen Energy., 37, 15339 (2012).

6. R. M. H. Khorasany, Y. Singh, A. Sadeghi Alavijeh, E. Kjeang, G. G. Wang, and R. K. N. D. Rajapakse, "Fatigue properties of catalyst coated membranes for fuel cells: Ex-situ measurements supported by numerical simulations," Int. J. Hydrogen Energy., 41, 8992 (2016).

7. F. A. De Bruijn, V. A. T. Dam, and G. J. M. Janssen, "Review: Durability and degradation issues of PEM fuel cell components," Fuel Cells., 8, 3 (2008).

8. A. Collier, H. Wang, X. Zi Yuan, J. Zhang, and D. P. Wilkinson, "Degradation of polymer electrolyte membranes," Int. J. Hydrogen Energy., 31, 1838 (2006).

9. D. A. Schiraldi, "Perfluorinated polymer electrolyte membrane durability," Polym. Rev., 46, 315 (2006).

10. M. P. Rodgers, L. J. Bonville, H. R. Kunz, D. K. Slattery, and J. M. Fenton, "Fue cell perfluorinated sulfonic acid membrane degradation correlating accelerated stress testing and lifetime," Chem. Rev., 112, 6075 (2012).

11. T. Ishimoto and M. Koyama, "A review of molecular-level mechanism of membrane degradation in the polymer electrolyte fuel cell," Membranes (Basel)., 2, 395 (2012).

12. A. A. Franco, M. L. Doublet, and W. G. Bessler, eds., Physical multiscale modeling and numerical simulation of electrochemical devices for energy conversion and storage: from theory to engineering to practice, Springer, London, 2015. 
13. A. Gooneie, S. Schuschnigg, and C. Holzer, "A review of multiscale computational methods in polymeric materials," Polymers (Basel). 9 (2017).

14. M. Danilczuk, F. D. Corns, and S. Schlick, "Visualizing chemical reactions and crossover processes in a fuel cell inserted in the esr resonator: Detection by spin trapping of oxygen radicals, nafion-derived fragments, and hydrogen and deuterium atoms," J. Phys. Chem. B., 113, 8031 (2009).

15. A. Ohma, S. Yamamoto, and K. Shinohara, "Membrane degradation mechanism during open-circuit voltage hold test," J. Power Sources., 182, 39 (2008).

16. N. Macauley, L. Ghassemzadeh, C. Lim, M. Watson, J. Kolodziej, M. Lauritzen, S. Holdcroft, and E. Kjeang, "Pt Band Formation Enhances the Stability of Fuel Cell Membranes," ECS Electrochem. Lett., 2, F33 (2013).

17. S. Kundu, M. W. Fowler, L. C. Simon, R. Abouatallah, and N. Beydokhti, "Degradation analysis and modeling of reinforced catalyst coated membranes operated under OCV conditions," J. Power Sources., 183, 619 (2008).

18. A. A. Shah, T. R. Ralph, and F. C. Walsh, "Modeling and simulation of the degradation of perfluorinated ion-exchange membranes in PEM fuel cells," J. Electrochem. Soc., 156, B465 (2009).

19. R. Coulon, W. Bessler, and A. A. Franco, "Modeling Chemical Degradation of a Polymer Electrolyte Membrane and its Impact on Fuel Cell Performance," ECS Trans., 25, 259 (2010).

20. M. Gummalla, V. V Atrazhev, D. Condit, N. Cipollini, T. Madden, N. Y. Kuzminyh, D. Weiss, and S. F. Burlatsky, "Degradation of Polymer-Electrolyte Membranes in Fuel Cells: II. Theoretical Model," J. Electrochem. Soc., 157, B1542 (2010).

21. M. A. Quiroga, K. Malek, and A. A. Franco, "A Multiparadigm Modeling Investigation of Membrane Chemical Degradation in PEM Fuel Cells," J. Electrochem. Soc., 163, F59 (2016).

22. L. Ghassemzadeh, K. D. Kreuer, J. Maier, and K. Muller, "Chemical Degradation of Nation Membranes under Mimic Fuel Cell Conditions as Investigated by Solid-State NMR Spectroscopy," J. Phys. Chem. C., 114, 14635 (2010).

23. L. Ghassemzadeh, T. J. Peckham, T. Weissbach, X. Luo, and S. Holdcroft, "Selective formation of hydrogen and hydroxyl radicals by electron beam irradiation and their reactivity with perfluorosulfonated acid ionomer," J. Am. Chem. Soc., 135, 15923 (2013).

24. L. Ghassemzadeh and S. Holdcroft, "Quantifying the structural changes of perfluorosulfonated acid ionomer upon reaction with hydroxyl radicals," J. Am. Chem. Soc., 135, 8181 (2013).

25. C. Lim, L. Ghassemzadeh, F. Van Hove, M. Lauritzen, J. Kolodziej, G. G. Wang, S. Holdcroft, and E. Kjeang, "Membrane degradation during combined chemical and mechanical accelerated stress testing of PEM fuel cells," J. Power Sources., 257, 102 (2014).

26. A. A. Shah, P. C. Sui, G. S. Kim, and S. Ye, "A transient PEMFC model with CO poisoning and mitigation by O2bleeding and Ru-containing catalyst," J. Power Sources., 166, 1 (2007).

27. A. A. Shah and F. C. Walsh, "A model for hydrogen sulfide poisoning in proton exchange membrane fuel cells," J. Power Sources., 185, 287 (2008).

28. D. E. Curtin, R. D. Lousenberg, T. J. Henry, P. C. Tangeman, and M. E. Tisack, "Advanced materials for improved PEMFC performance and life," J. Power Sources. 131, 41 (2004).

29. P. C. Sui, S. Kumar, and N. Djilali, "Advanced computational tools for PEM fuel cell design. Part 1. Development and base case simulations," J. Power Sources., 180, 410 (2008).

30. M. Inaba, T. Kinumoto, M. Kiriake, R. Umebayashi, A. Tasaka, and Z. Ogumi, "Gas crossover and membrane degradation in polymer electrolyte fuel cells," Electrochim. Acta., 51, 5746 (2006).

31. C. K. Mittelsteadt and H. Liu, Conductivity, permeability, and ohmic shorting of ionomeric membranes, in: Handb. Fuel Cells - Fundam. Technol. Appl., 2009: p. 345 .
32. Z. Ogumi, T. Kuroe, and Z. Takehara, "Gas Permeation in SPE Method: II. Oxygen and Hydrogen Permeation Through Nafion," J. Electrochem. Soc., 132, 2601 (1985).

33. J. Zhang, H. A. Gasteiger, and W. Gu, "Electrochemical Measurement of the Oxygen Permeation Rate through Polymer Electrolyte Membranes," J. Electrochem. Soc., 160, F616 (2013).

34. V. A. Sethuraman, J. W. Weidner, A. T. Haug, S. Motupally, and L. V. Protsailo, "Hydrogen Peroxide Formation Rates in a PEMFC Anode and Cathode," J. Electrochem. Soc., 155, B50 (2008).

35. W. Liu and D. Zuckerbrod, "In Situ Detection of Hydrogen Peroxide in PEM Fuel Cells," J. Electrochem. Soc., 152, A1165 (2005).

36. K. H. Wong and E. Kjeang, "Mitigation of chemical membrane degradation in fuel cells: Understanding the effect of cell voltage and iron ion redox cycle," ChemSusChem., 8, 1072 (2015).

37. K. H. Wong and E. Kjeang, "Macroscopic In-Situ Modeling of Chemical Membrane Degradation in Polymer Electrolyte Fuel Cells," J. Electrochem. Soc., 161, F823 (2014).

38. M. D. Hurley, M. P. S. Andersen, T. J. Wallington, D. A. Ellis, J. W. Martin, and S. A. Mabury, "Atmospheric chemistry of perfluorinated carboxylic acids: Reaction with OH radicals and atmospheric lifetimes," J. Phys. Chem. A., 108, 615 (2004).

39. R. Coulon, Modélisation de la dégradation chimique de membranes dans les piles à combustibles à membrane électrolyte polymère, Ph.D. dissertation, Université de Grenoble, 2012.

40. V. V Atrazhev, N. S. Erikhman, and S. F. Burlatsky, "The potential of catalytic particle in ion exchange membrane," J. Electroanal. Chem., 601, 251 (2007).

41. V. O. Mittal, H. Russell Kunz, and J. M. Fenton, "Is $\mathrm{H}_{2} \mathrm{O}_{2}$ Involved in the Membrane Degradation Mechanism in PEMFC?," Electrochem. Solid-State Lett., 9, A299 (2006).

42. J. Zhang, B. A. Litteer, F. D. Coms, and R. Makharia, "Recoverable Performance Loss Due to Membrane Chemical Degradation in PEM Fuel Cells," J. Electrochem. Soc., 159, F287 (2012).

43. L. Gubler and W. H. Koppenol, "Kinetic Simulation of the Chemical Stabilization Mechanism in Fuel Cell Membranes Using Cerium and Manganese Redox Couples," J. Electrochem. Soc., 159, 211 (2012).

44. K. H. Wong and E. Kjeang, "In-Situ Modeling of Chemical Membrane Degradation and Mitigation in Ceria-Supported Fuel Cells," J. Electrochem. Soc., 164, F1179 (2017).

45. K. K. Poornesh and C. Cho, "Stability of polymer electrolyte membranes in fuel cells: Initial attempts to bridge physical and chemical degradation modes," Fuel Cells., 15, 196 (2015).

46. I. A. Amin, J. C. Juan, and C. W. Lai, An overview of chemical and mechanical stabilities of polymer electrolytes membrane, in: Org. Compos. Polym. Electrolyte Membr. Prep. Prop. Fuel Cell Appl., 2017: pp. 327.

47. R. Singh, A. R. Akhgar, P. C. Sui, K. J. Lange, and N. Diilali, "Dual-Beam FIB/SEM Characterization, Statistical Reconstruction, and Pore Scale Modeling of a PEMFC Catalyst Layer," J. Electrochem. Soc., 161, F415 (2014).

48. A. Nanjundappa, A. S. Alavijeh, M. El Hannach, D. Harvey, and E. Kjeang, "A customized framework for 3-D morphological characterization of microporous layers," Electrochim. Acta., 110, 349 (2013).

49. H. Sadeghifar, N. Djilali, and M. Bahrami, "Effect of Polytetrafluoroethylene (PTFE) and micro porous layer (MPL) on thermal conductivity of fuel cell gas diffusion layers: Modeling and experiments," J. Power Sources., 248, 632 (2014)

50. E. N. Fuller, P. D. Schettler, and J. C. Giddings, "A new method for prediction of binary gas-phase diffusion coefficients," Ind. Eng. Chem., 58, 18 (1966).

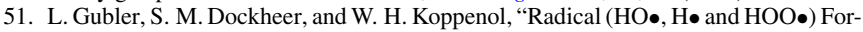
mation and Ionomer Degradation in Polymer Electrolyte Fuel Cells," J. Electrochem. Soc., 158, B755 (2011).

52. P. Maruthamuthu, S. Padmaja, and R. E. Huie, "Rate constants for some reactions of free radicals with haloacetates in aqueous solution," Int. J. Chem. Kinet., 27, 605 (1995). 